\title{
Annotation
}

\section{Should handicapped children attend ordinary schools?}

The Warnock report ${ }^{1}$ has raised many issues relevant to child health. Among these are the arguments for and against the integration of handicapped children into ordinary schools. This aspect has been given topical prominence by the affirmation of the Secretary for Education of his support for the implementation of section 10 of the 1976 Education Act. ${ }^{2}$ This states that, subject to certain qualifications and from a date to be determined, handicapped pupils in England and Wales should be educated in ordinary schools in preference to special schools. It is appropriate therefore, that not only should the issue of integration be debated but also that the contexts in which such a development could occur be clarified.

\section{The present position}

Less than $20 \%$ of children, whether handicapped or not currently have preschool placement before they are 5 -years old, ${ }^{3-4}$ although this percentage must vary between one district and another. The preschool is not generally used more by handicapped children than by their healthy peers. ${ }^{3}$ Most of this preschool provision is by means of day nurseries and play groups, and neither usually includes teachers among their staff. The priority for preschool children therefore, may be considered as a general extension of educational facilities for all and not merely for the handicapped.

Many handicapped children aged between 5 years and school leaving age have already been integrated into normal schools. In $1977,12 \%$ of all children ascertained to be in need of special education were attending ordinary schools. Their handicaps were usually slight but extended across the whole range of disabilities. ${ }^{5}$ Any discussion relating to this group of children should be centred therefore, on the rationale and the methods for extending integration and for making it more effective, rather than on the underlying principle. The fact that the number of births in the UK has fallen over recent years should also be taken into consideration, although the birth rate may now be rising again. It should also be borne in mind that perinatal and paediatric policies have been directed towards the prevention of handicap, so it may well be that the number of children with special educational needs will be considerably smaller than it was a decade ago. This will make more places available in both ordinary and special schools, and the advantages and disadvantages of these placements will have an additional contemporary significance.

\section{For and against integration}

The difficulties of handicapped children attending ordinary schools have been vividly described by Kershaw. ${ }^{5}$ He stressed the vulnerability of such children, especially in terms of limitation of performance - which may be physical, academic, or both-and in terms of differences in expectation, both their own expectations and those of their families.and of school staff. Such difficulties are more likely to be overcome if the child's disability is slight and if the school staff and curriculum are flexible. There are social and educational benefits when such an integration is achieved. Educationally the potentially greater breath, depth, and pace of the teaching are obvious, especially when these are compared with the inroads made on educational time in so many special schools by the need to transport and mobilise the pupils, and take them to the lavatory. In such circumstances there is always the danger that the more able handicapped child will have to proceed at a slower pace than he need.

There is also the great advantage for the handicapped child at a normal school to have as his models children who are physically, mentally, and socially able. If integration is to become more extensive than at present however, more suitably trained teachers will need to be appointed as additional staff members in ordinary schools.

Socially the exposure of handicapped and normal children to each other may help integration beyond school as well as within it. Allied to this, the stigma of attending a special school persists in the minds of much of society, including the handicapped child himself, his parents, and his potential employers. The practice of transferring the handicapped child to an ordinary school in the years before he leaves, now increasingly practised, goes some way towards combating this stigma, in addition to providing relevant experiences for the child.

In any calculation of the advantages of integration 
it is necessary to evaluate the indications for and benefits of special school placement. Clearly the more handicapped the child, the more likely it is that such a placement will be needed but it would be wrong for such a situation to be interpreted negatively. Comprehensive assessment of the needs of children with severe and multiple handicaps implies appropriate planning and resources to fulfil their medical, educational, and social needs. That assessment must not merely be a labelling or placement exercise. Instead it should initiate the production of a profile of a child's abilities which can further be explored and extended in the classroom. From the schooling viewpoint it is therefore, reasonable to expect teachers who have a special educational qualification together with some of their supporting staff to plan a suitable curriculum and integrate it where necessary with other aspects of care-for example, parents' support groups, physiotherapy, and speech therapy. In special circumstances such integration could be the basis of the whole educational strategy, as in the Peto method of conductive education for children with cerebral palsy. ${ }^{6}$ Cues such as these are taken up by the Warnock report in its advocacy that some special schools should become resource centres for handicapped children. Such a proposal would correlate well with proposals for the creation of district handicap teams put forward in the Court report ${ }^{7}$ and already implemented to some extent.

\section{For the future}

Further integration of handicapped children into ordinary schools cannot be considered in isolation. Instead it must be viewed within the twin contexts of all the needs of children with handicaps, and of educational services and resources as a whole.

On the former count, programmes for prevention, identification, comprehensive assessment, management, and care (and education is involved with most of these) are far from fully developed. As a result children may well come to school entry with disabilities that are unidentified or are inappropriately managed. Circumstances such as these can clearly invalidate any integration policy and the Warnock report, rightly therefore, repeatedly stresses the importance of accurate assessment as a prerequisite to school placement.

The second context, that of educational services and resources as a whole, is equally important. It would be wrong for central government, or individual educational authorities to attempt to integrate handicapped children into normal schools as an inexpensive option and mainly for social gains. The Warnock report ${ }^{1}$ emphasised a number of priorities. These include a much wider provision of preschool education for both handicapped and normal children, special educational services that are more flexible and sensitive to the needs of individual handicapped children and their families, greater attention to the needs of handicapped adolescents, and more widespread and effective teacher training for special education. It would seem that action on these measures should be taken before there is any significant increase in the present degree of integration of handicapped children into ordinary schools.

\section{References}

1 Warnock M, chairman. Report of the Committee of Enquiry into the Education of Handicapped Children and Young People: Special educational needs. London: HMSO, 1978.

2 Anonymous. Help pledged for handicapped at school. Daily Telegraph 1980, March 4: 8 (col 2).

3 Clark M M. A research project on pre-school education and handicapped and exceptional children. In: Warnock M, chairman. Report of the Committee of Enquiry into the Education of Handicapped Children and Young People: Special educational needs. London: HMSO, 1978: 389-90.

+ Stephenson J, Ellis C. Which 3 year olds attend pre-school facilities? Child Care Health Dev 1975; 1 : 397-411.

5 Kershaw J. Handicapped children in the ordinary school. In: Varma V P, ed. Stresses in children. London: University Press, 1973; 1-20.

6 Cotton E. Integration and treatment in education in cerebral palsy. Physiotherapy 1970 ; 56: 1-5.

7 Court C D M, chairman. Report of the Committee on Child Health Services: Fit for the future. London: HMSO, 1976.

L Rosenbloom

Department of Neurology and Child Development Centre, Alder Hey Children's Hospital, Eaton Road, Liverpool L12 $2 A P$ 